BIBECHANA

A Multidisciplinary Journal of Science, Technology and Mathematics

ISSN 2091-0762 (online)

Journal homepage: http://nepjol.info/index.php/BIBICHANA

\title{
Anomalous seismic activity associated with 1988 Udayapur earthquake
}

\section{Harihar Paudyal*}

Dept. of Physics, Birendra Multiple Campus, (Tribhuvan University) Bharatpur, Chitwan, Nepal

Article History: Accepted 5 December 2010

\begin{abstract}
The Udayapur earthquake of August 20, $1988\left(\mathrm{M}_{\mathrm{b}}\right.$ 6.4, Ms 6.6, Origin time: 23:09:10, epicenter at $26.8{ }^{\circ} \mathrm{N} 86.6{ }^{\circ} \mathrm{E}$ and Focal depth $57 \mathrm{~km}$ ) occurred in the Himalayan front arc which caused severe damage in the region will loss of 1100 lives. In the same epicentral region, a strong event of $\mathrm{m}_{\mathrm{b}} 5.4$ has occurred on 20 April 1988. Anomalous seismic activity associated with these earthquake in Eastern Nepal and its adjoining region in an area bounded by $26.0^{\circ}-29.0^{\circ} \mathrm{N}$ and $84.6^{\circ}-88.4^{\circ} \mathrm{E}$ have been studied using seismicity data from $1975-1988$. The preparatory zone is delineated using the temporal and the spatial distribution of earthquakes, considering the events with cutoff magnitude $m_{b} \geq 4.3$. Based on daily number of events as well as cumulative number of earthquake with time within the preparatory zone anomalous seismicity is recognized. Accordingly four anomalous episodes: Normal/ background (N); Anomalous/ swarm (A); Precursory gap $(\mathrm{G})$ and Mainshock sequence $(\mathrm{M})$ are identified. It is observed that the first mainshock $\left(m_{b} 5.4\right)$ was related to the second mainshock $\left(m_{b} 6.4\right)$ which was preceded by well defined patterns of anomalous seismicity/ precursory swarm which commenced about ten years and six months prior to mainshock.
\end{abstract}

\section{Keywords: Anomalous seismicity; Central Himalaya; South Eastern Nepal; Precursory swarm}

\section{Introduction}

Four great earthquakes and a large number of major earthquakes have occurred in the Himalayan region since 1897 . The seismic activity in the region is directly related to the collision between Indian and Tibetan plate. Three northward dipping thrusts, i.e. Main Central Thrust (MCT), Main Boundary Thrust (MBT) and Main Frontal Thrust (MFT), are the continuous structure throughout the Himalayan range having offset at many places by nearly N-S transverse fault. Seismic activity within the region is due to release of stress along the major faults and lineaments.

A number of seismic precursors are known to precede medium to large earthquakes $[1,2]$. Anomalous seismicity is the first to take place as compared to other precursory phenomena due to

\footnotetext{
* Corresponding author: Dr. Harihar Paudyal, Dept. of Physics, Birendra Multiple Campus, (Tribhuvan University) Bharatpur, Chitwan, Nepal, Email: hariharpaudyal@ gmail.com
} 


\section{Harihar Paudyal / BIBECHANA 7 (2011) 76-82: BMHSS}

formation of various ruptures where considerable strain energy is accumulated [3]. Noticeable fluctuations in seismicity, mostly prior to significant earthquakes, have been observed in various regions of the world. Hence it may be an important parameter for the prediction of long-range earthquake related hazards in a region. The phenomenon of seismic quiescence, in which seismic activity drops to almost zero, has often been observed prior to the mainshock. The quiescence is often broken by stress buildup resulting in an increase in the number of earthquakes, known as pre-shocks. Such seismic quiescence often ends with foreshock activity that takes place just before the mainshock. The seismicity level drops to a low background level after the completion of a mainshock sequence.

Anomalous seismicity pattern has some kind of casual relationship with the time of occurrence and magnitude of the mainshock. Such patterns follow episodes of relatively very low seismic activity, which is an important finding to visualize that an area might be preparing for the forthcoming mainshock. The patterns of anomalous seismicity/ earthquake swarms can be considered as an important parameter for the forecasting of long-range earthquake hazards in the region. If any region is observed in which anomalously low precursory quiescence period is continuing, efforts have been made to search for other short term premonitory phenomena.

A burst of seismic activity reflects the onset of the precursory sequence that follows a period of abnormal quiescence which continues till the occurrence of the major event $[4,5]$. The entire preparatory period may be classified into four episodes as: Normal (or background) seismicity sequence (measured till the onset of swarm activity); anomalous seismicity (or precursory swarm) sequence (period from the onset to end of swarm activity); precursory gap (or seismic quiescence) sequence (from the date of termination of swarm activity to the onset of the mainshock sequence); and the mainshock sequence (duration of mainshock and its associated aftershocks) [4]. Within the preparatory area, the episodes of normal (N), anomalous (A), gap (G) and mainshock (M) sequences represent anomalously low, high, low and high seismic activities, respectively.

A precursory earthquake swarm occurs in and around the focal region of a major earthquake several years before its occurrence [4, 5]. Evison [6] proposed a generalized precursory swarm hypothesis for the occurrence of multiple earthquake swarms, precursory gap and multiple mainshock events. The hypothesis was tested in Japan and New Zealand $[7,8,9]$ and updated accordingly. Following a similar methodology, several cases of the earthquake swarm pattern were reported in different parts of Himalaya and its adjoining region, such as: Singh et al. for Burma Szechwan region [10]; Singh and Singh [11, 12] for Pamir and its adjoining region; Gupta and Singh [13,14] for Eastern Himalaya and recently Singh et al. [15] for Western Nepal in Central Himalaya.

In the present study, the existence of anomalous seismicity patterns in the region prior to the occurrence of 1988 Udayapur earthquake is examined. The earthquake database compiled for Central Himalaya region by Paudyal [16] using existing catalogues of NEIC, National Seismological Center (NSC) and International Seismological Center (ISC) has been used for the identification of seismicity patterns. In the Central Himalaya regions, the cutoff magnitude for the period 1963-2006 is estimated to be $m_{b} \geq 4.3$ using b-value method [16]. Hence only earthquakes with $m_{b} \geq 4.3$ have been considered for identifying seismic anomalies.

\section{Udayapur Earthquakes of 20 Aug. $1988\left(m_{b} 6.4\right)$ and 20 April $1988\left(m_{b} 5.4\right)$}

The Udayapur earthquake of 20 August 1988 is the largest one in the recent time that occurred in the southeastern Nepal and caused widespread devastation in the adjoining areas of the Nepal and India. Prior to this, an earthquake of $m_{b} 5.4$ has occurred $\sim 30 \mathrm{~km}$ to the north of the epicenter of the Udayapur earthquake on 20 April 1988. These two earthquakes have occurred in the epicentral tract of 1934 great earthquake. In order to investigate anomalous seismic patterns associated with these two recent earthquakes, the seismicity data for the period 1975 to 1988 
falling within an area bounded by $26^{\circ}-29^{\circ} \mathrm{N}$ and $84.6^{\circ}-88.4^{\circ} \mathrm{E}$ is considered. The spatial distribution of events during the considered period is located in the northwest-southeast direction including both the mainshocks. An elliptical area oriented in the same direction is delineated as the preparatory area $\left(\sim 4.7 \times 10^{4} \mathrm{~km}^{2}\right)$ for the 1988 Udayapur earthquake which encloses most of the events during the period (Fig. 1). The temporal pattern, shown in Fig. 2a, clearly shows a significant increase in the seismic activity during the two periods i.e. from 10 February 1978 to 19 June 1979 (495 days) and 23 December 1985 to 02 February 1986 (52 days) (Tables 1 and 2). The first high active phase is found to be related with 20 August 1988 mainshock and the second one with the 20 April 1988 mainshock. The second anomalous high activity, both in the space and time, occurred well within the preparatory area of the 20 August 1988 mainshock during its gap episode.

Four anomalous episodes associated with 20 August 1988 mainshock identified as normal seismicity, anomalous/ swarm, gap and mainshock sequence based on critical examination of the spatial and the temporal distributions of events are furnished in Table 1 . The temporal pattern of events and their magnitude relationship within the preparation area is depicted in Fig. 2a show that the seismicity preceding mainshock fluctuated in the order as low-high-low in the ratio 1:4:1 during the normal, anomalous and gap episodes, respectively. The anomalous seismic activity (swarm sequence) initiated about ten and half years prior to the mainshock that lasted for 495 days. Though the number of seismic events in the anomalous episode within the delineated preparatory area is not very large but it is characterized by the four fold higher seismicity over the preceding normal and the following gap episodes.

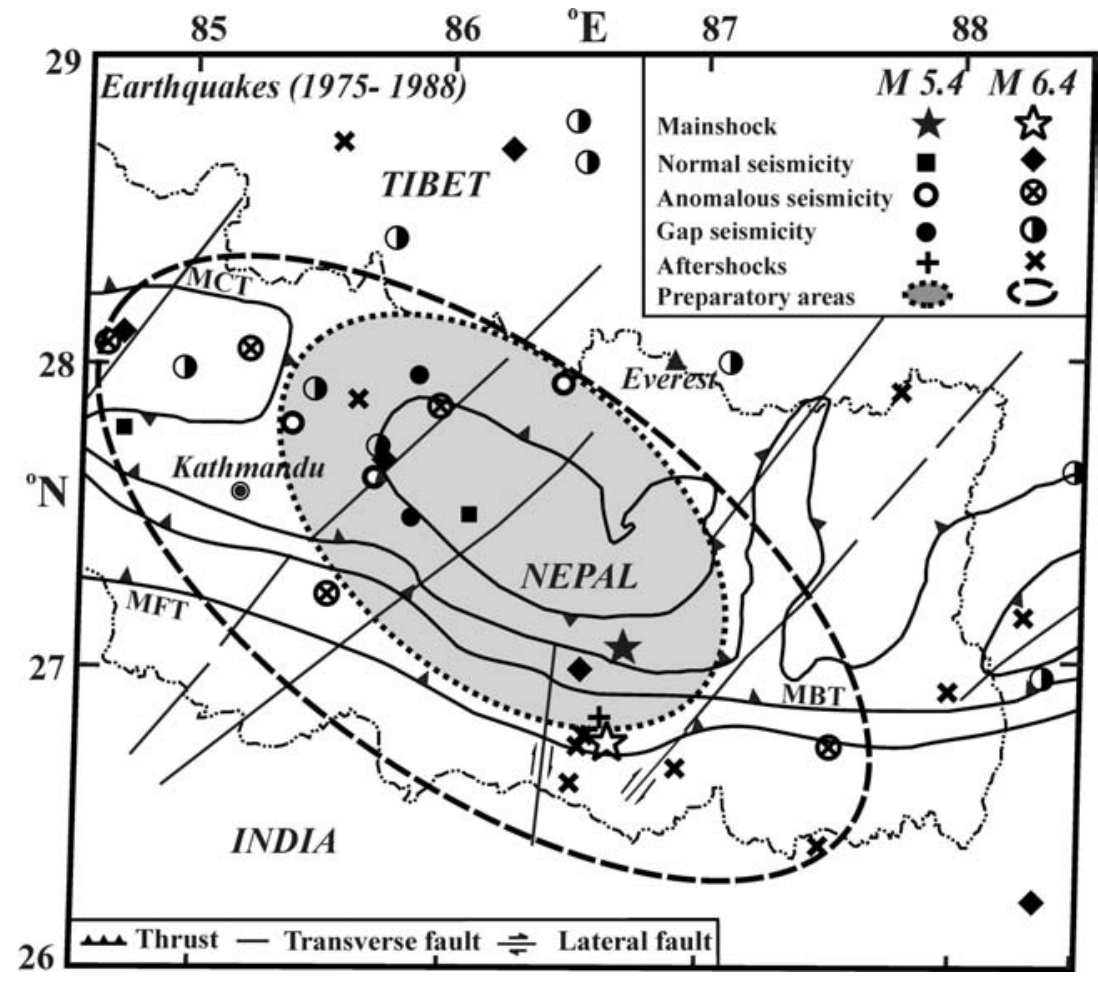

Figure 1: Spatial distribution of events $\left(m_{b} \geq 4.3\right)$ for the period 1975-1988 associated with the mainshock of 20 April $1988\left(\mathrm{~m}_{\mathrm{b}}\right.$ 5.4) and 20 August $1988\left(\mathrm{~m}_{\mathrm{b}}\right.$ 6.4) in Udayapur region, Eastern Nepal. The smaller (shaded) and larger dotted elliptical region are the preparatory areas for the mainshocks of 20 April 1988 and 20 August 1988 respectively delineated based on spatial distribution of normal $(\mathrm{N})$, swarm/ anomalous seismicity (A), gap $(\mathrm{G})$ and the mainshock sequences $(\mathrm{M})$ on the surface. 
Leaving a seismic gap in the southeastern part of the preparatory area, the seismic events in all the episodes are widely distributed but mostly concentrated in the northwestern portion. The magnitude of events in the swarm sequence range from 4.3 to 5.2; whereas an event with M 5.4 (which is the second mainshock) has occurred on 20 April 1988 during the gap period which itself was found to be preceded by the anomalous swarm activity some $26 \frac{1}{2}$ months prior to the mainshock. Four out of five events in the swarm sequence are located in between $84.5^{\circ}$ to $86^{\circ} \mathrm{E}$ at about $33 \mathrm{~km}$ depth, whereas the remaining one is located far away within the preparatory area around $87.5^{\circ} \mathrm{E}$ at a depth of $24 \mathrm{~km}$. The mainshock occurred on 20 August 1988 after a precursory gap period of 3,349 days in the southern part of the preparatory area at a depth of 57 $\mathrm{km}$ close to the MFT and to the south of largest gap event. Aftershocks are confined in the depth range of 30-45 km around the mainshock (Fig. 2b). Based on these information, it is inferred that the mainshock of 20 August 1988 was preceded by the anomalous seismic activity/ earthquake swarms which commenced about $101 / 2$ years before the mainshock. The aftershocks and the anomalous seismic events occupy the eastern and the western parts of the preparatory area, respectively.

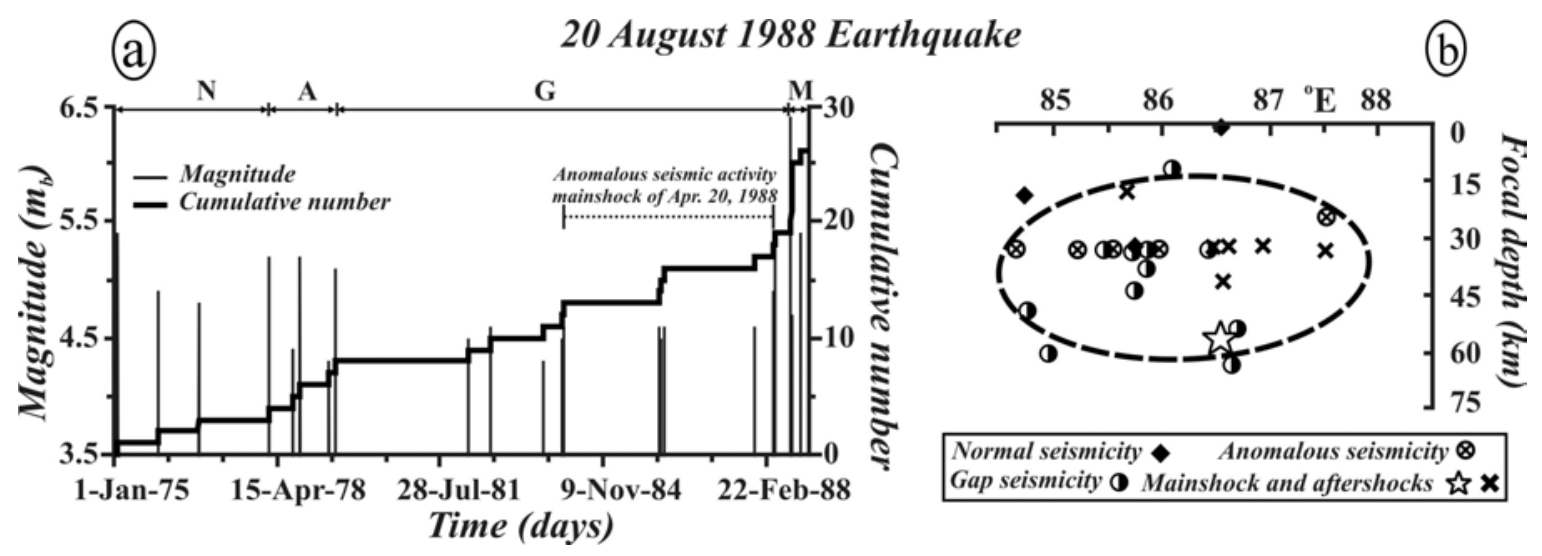

Figure 2: Temporal (a) and focal depth (b) distribution of events $\left(m_{b} \geq 4.3\right)$ for the period 1975-1988 associated with the mainshock of 20 August $1988\left(\mathrm{~m}_{\mathrm{b}} 6.4\right)$ in Udayapur region, Eastern Nepal. Four identified anomalous sequences are: Normal/ background seismicity $(\mathrm{N})$; Precursory swarm (A); Precursory gap or quiescence (G); and Mainshock and its associated aftershocks (M).

The seismicity data from 1984 to 1988 is considered here to study the earthquake swarm/ anomalous seismic activity associated with the mainshock of 20 April 1988. This event occurred close to the surface trace of the MCT at $27^{\circ} \mathrm{N}$ and $86.7^{\circ} \mathrm{E}$ (Fig. 1). It is observed here that this earthquake was preceded by a swarm sequence which occurred within the continuing precursory gap period associated with 20 August 1988 Udaypur mainshock. This is a clear case of an earthquake swarm in which another swarm sequence occurs at a later stage, principally in the continuing gap episode of the first one. All the characteristic events (Table 2) related with the 20 April 1988 mainshock are the gap events of 20 August 1988 mainshock as shown in Figs. 2a and 3a. The delineated preparatory area $\left(\sim 2 \times 10^{4} \mathrm{~km}^{2}\right)$ for this earthquake falls completely within the preparatory area of 20 August 1988 mainshock, and has similar orientation along the northwestsoutheast (Fig. 1). The temporal pattern of events and their magnitude relationships within the preparation area depicted in Fig. 3a show that the seismicity preceding mainshock in the normal, swarm and gap episodes fluctuated in the order as low-high-low in the ratio of 1:41:2, respectively as normalized on annual basis. The precursory swarm events are distributed in the western part of the preparatory area and their magnitude range from 4.5 to 4.6. The mainshock has occurred in the southeast portion of the preparatory area after a quiescence of 807 days from the termination of the anomalous phase. The swarm and the gap events are clustered in the depth 
range 30-45 km; whereas the mainshock has occurred at deeper level at $54 \mathrm{~km}$ (Fig. 3b). Only one aftershock is reported to occur at deeper focal depth $(66 \mathrm{~km})$ to the south of mainshock and very close to mainshock of 20 August 1988. The above observations suggest that the mainshock of 20 April 1988 was preceded by an earthquake swarms/ anomalous seismic activity which commenced about two years and four months before the mainshock.

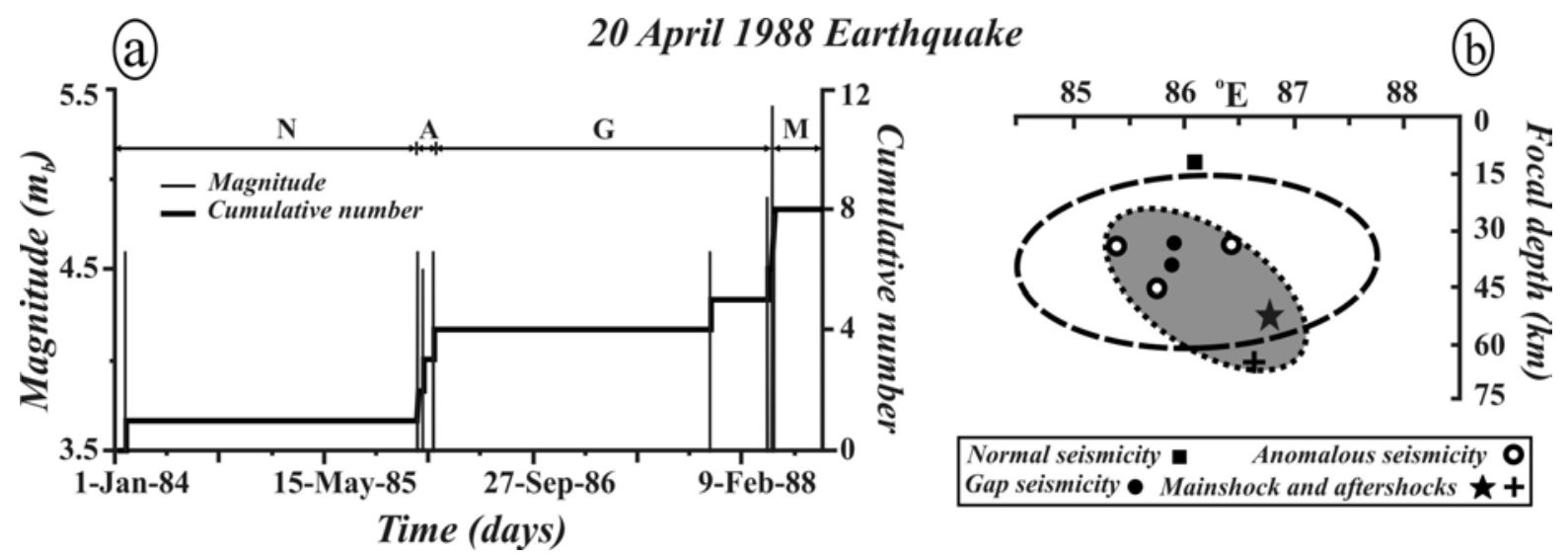

Figure 3: Temporal (a) and focal depth (b) distribution of events $\left(\mathrm{m}_{\mathrm{b}} \geq 4.3\right)$ for the period 1984-1988 associated with the mainshock of 20 April $1988\left(m_{b} 5.4\right)$ in Udayapur region, Eastern Nepal. Four identified anomalous sequences are: Normal/ background seismicity $(\mathrm{N})$; Precursory swarm (A); Precursory gap or quiescence (G); and Mainshock and its associated aftershocks (M).

Table 1: Seismic characteristics in the identified episodes within the preparatory area of mainshock of 20 August 1988 in Udayapur region, Nepal.

\begin{tabular}{|c|c|c|c|c|}
\hline Seismic episodes & Duration & $\begin{array}{l}\text { D } \\
\mathbf{a} \\
\mathbf{y} \\
\mathbf{s}\end{array}$ & $\begin{array}{l}\text { T } \\
\text { ot } \\
\text { al } \\
\text { ev } \\
\text { en } \\
\text { ts }\end{array}$ & $\begin{array}{l}\text { Level of } \\
\text { activity }\end{array}$ \\
\hline $\begin{array}{l}\text { Normal/ background } \\
\text { (N) }\end{array}$ & $\begin{array}{l}\text { 01 Jan. 1975-09 } \\
\text { Feb.1978 }\end{array}$ & $\begin{array}{l}1 \\
1 \\
3 \\
6 \\
\end{array}$ & 3 & $\begin{array}{l}\text { Moderately } \\
\text { low }\end{array}$ \\
\hline $\begin{array}{l}\text { Anomalous/ swarm } \\
\text { (A) }\end{array}$ & $\begin{array}{c}10 \text { Feb.1978-19 Jun. } \\
1979\end{array}$ & $\begin{array}{l}4 \\
9 \\
5 \\
\end{array}$ & 5 & $\begin{array}{l}\text { Moderately } \\
\text { high }\end{array}$ \\
\hline Precursory gap (G) & $\begin{array}{l}20 \text { Jun.1979-19 } \\
\text { Aug.1988 }\end{array}$ & $\begin{array}{l}3 \\
3 \\
4 \\
9\end{array}$ & 11 & $\begin{array}{l}\text { Moderately } \\
\text { low }\end{array}$ \\
\hline $\begin{array}{l}\text { Mainshock sequence } \\
\text { (M) }\end{array}$ & $\begin{array}{l}20 \text { Aug.1988-27 } \\
\text { Dec. } 1988\end{array}$ & $\begin{array}{l}1 \\
3 \\
0\end{array}$ & 7 & - \\
\hline
\end{tabular}


Table 2: Seismic characteristics in the identified episodes within the preparatory area of mainshock of 20 April $1988\left(m_{b} 5.4\right)$ in Udayapur region, Nepal.

\begin{tabular}{|c|c|c|c|c|}
\hline Seismic episodes & Duration & $\begin{array}{l}\text { D } \\
\mathbf{a} \\
\mathbf{y} \\
\mathbf{s}\end{array}$ & $\begin{array}{l}T \\
\text { ot } \\
\text { al } \\
\text { ev } \\
\text { en } \\
\text { ts }\end{array}$ & $\begin{array}{l}\text { Level of } \\
\text { activity }\end{array}$ \\
\hline $\begin{array}{l}\text { Normal/ background } \\
\text { (N) }\end{array}$ & $\begin{array}{l}\text { 01 Jan.1984-22 } \\
\text { Dec.1985 }\end{array}$ & $\begin{array}{l}7 \\
1 \\
2\end{array}$ & 1 & $\begin{array}{l}\text { Extremely } \\
\text { low }\end{array}$ \\
\hline $\begin{array}{l}\text { Anomalous/ swarm } \\
\text { (A) }\end{array}$ & $\begin{array}{l}23 \text { Dec.1985-02 } \\
\text { Feb.1986 }\end{array}$ & $\begin{array}{l}5 \\
2\end{array}$ & 3 & $\begin{array}{l}\text { Extremely } \\
\text { high }\end{array}$ \\
\hline Precursory gap (G) & $\begin{array}{l}03 \text { Feb.1986-19 } \\
\text { Apr.1988 }\end{array}$ & $\begin{array}{l}8 \\
0 \\
7\end{array}$ & 2 & $\begin{array}{l}\text { Extremely } \\
\text { low }\end{array}$ \\
\hline $\begin{array}{l}\text { Mainshock sequence } \\
\text { (M) }\end{array}$ & $\begin{array}{l}\text { 20 Apr.1988-25 } \\
\text { Apr.1988 }\end{array}$ & 6 & 2 & - \\
\hline
\end{tabular}

There have been several marked similarities in the occurrence pattern of anomalous seismic activity preceding the mainshocks of 20 April 1988 and 20 August 1988 as: 1) preparatory areas have similar orientation along the northwest-southeast; 2) almost all events in the preceding episodes occurred in the northwest side whereas both the mainshocks occurred opposite side in the southeast part of the preparatory areas; 3 ) the majority of the preceding events occurred at shallower levels as compared to the mainshocks which occurred at a greater focal depths (54 and $57 \mathrm{~km}$ ). Considering the above similarities, it may be concluded that both the mainshocks were preceded by the different swarm sequences at two different times within the larger preparatory area. Further, it demonstrates that the entire preceding seismic activities, including the second swarm sequence and the associated mainshock, are related to the 20 August 1988 mainshock and appears to be caused by the same triggering mechanism.

\section{Conclusion}

The spatial and temporal changes in seismic activity may be causally related to the time of occurrence and the magnitude of the mainshocks. In view of this, an attempt has been made here to search for the pattern of the seismicity changes in space and time domains prior to Udayapur earthquake. The earthquake was found to be associated with a well defined anomalous seismic activity both in space and time during 11.02.1978 to 19.06.1979 some three years and four months prior to the mainshock. The seismicity fluctuated in the order of low-high-low-high in the characteristics four phases from 1975 to 1988. The anomalous seismic phase within the preparatory zone was characterized by considerably high seismicity as compared to its preceding background seismicity phase and the following precursory gap phase. 
Harihar Paudyal / BIBECHANA 7 (2011) 76-82: BMHSS

\section{Acknowledgement}

The author is grateful to Associate Prof. Dr. HN Singh, Department of Geophysics, Banaras Hindu University India for offering useful comments and suggestions.

\section{References}

[1] T. Rikitake, Earthquake prediction, Elsevier, Amsterdam,(1976)357

[2] T. Rikitake, Earthquake Forecasting and Warning., Center for Academic Publications, Japan,(1982)402.

[3] H. Sekiya, J. Phys. Earth, 25(1977) S85-S93.

[4] F. F. Evison, Nature ,266 (1977a) 710.

[5] F. F. Evison, The precursory earthquake swarm, Physics of the Earth and Planetary Interiors, 15(1977b) 19.

[6] F. F. Evison, J. Physics of the Earth, 30 (1982) 155.

[7] F. F Evison and D. A. Rhoades, Earth Planets Space, 51 (1999) 1267.

[8] F. F. Evison and D. A. Rhoades, J. Geology and Geophysics, 40 (1997) 537.

[9] F. F. Evison and D. A. Rhoades, J. Geology and Geophysics, 36 (1993) 51.

[10] V. P. Singh, H. N. Singh and J. Singh, Tectonophysics, 85(1982) T21-T29.

[11] V. P. Singh and H. N. Singh, Tectonophysics, 113 (1985 )295.

[12] V. P. Singh and H. N. Singh, Earthquake Prediction Research, 4(1986) 83.

[13] H. K. Gupta and H. N. Singh, J. Geol. Soc. India , 28 (1986) 367.

[14] H. K. Gupta and H. N. Singh, Tectonophysics, 167 (1989) 285.

[15] H. N. Singh, H. Paudyal, D. Shankar, A. Panthi and A. Kumar, Pure and Applied Geophysics, 167 ( 2010$) 667$.

[16] H. Paudyal, Seismicity and seismotectonics of Nepal and its adjoining region $\mathrm{Ph}$. D. Thesis, Department of Geophysics, Faculty of Science, Banaras Hindu University, Varanasi, India( 2008). 